\title{
CORRESPONDENCE
}

\section{OPEN-ANGLE GLAUCOMA}

\section{To the Editorial Committee of the BrITISH JouRNAL OF OPHTHALMOLOGY}

SIRS,-Many different operations have been described for open-angle glaucoma, showing that none is entirely satisfactory. The recurrence rate is low among the white races but reaches a very high figure amongst the brown and black races, and much ingenuity has been devoted to trying to find a solution (Epstein (1959)).

Five months ago, following on the good results obtained by the use of beta ray in pterygia, it was decided to use beta ray in recurrent glaucoma. A man aged 69 had a left sclerectomy $(4 \times 1 \mathrm{~mm}$.) with peripheral iridectomy performed in August, 1958, for openangle glaucoma. The pre-operative tension was $45 \mathrm{~mm}$. $\mathrm{Hg}$ Schiötz, but, after an initial post-operative fall for 3 months, the former level was slowly regained. The bleb eventually disappeared and the tension reached $60 \mathrm{~mm}$. $\mathrm{Hg}$ Schiötz. Accordingly, on October 1, 1959, a conjunctival flap was turned down over the former operation site at 12 o'clock, and a small dot of gentian violet made on the sclera at the projected site of drainage. A small piece of lead foil with a 5-mm. circular hole was placed on the sclera, with the hole over the gentian violet dot. A beta-ray applicator was applied over the hole in the lead foil and a single dose of 2,000r was given in 2 minutes. A hole was burned through the sclera at the gentian violet dot with a cautery point (Preziosi) and the conjunctival flap was reflected back to its original position and sutured. There was a good bleb at the first post-operative dressing. This has remained since, and 5 months later the post-operative ocular tension is $25 \mathrm{~mm}$. Hg Schiötz.

My attention has recently been drawn to an article entitled "Beta Radiation as an Adjunct to Glaucoma Surgery in the Negro" (Cohen, Graham, and Fry, 1959) in which it is stated that eight out of ten Negroes were successfully operated on for glaucoma, using beta ray with sclerectomy by scleral punch and iridencleisis.

In twelve cases of pterygia, treated by the same dose of beta ray 10 years ago in Cairns, Australia, there has since been no cataract formation or any other complication.

The Preziosi operation is the simplest of the operations for glaucoma, but has never been popular because of the rather high recurrence rate. I believe that the addition of the beta ray procedure will give it a new lease of life. There will always be those eyesurgeons who love to devise ingenious and complicated procedures, but to those who desire the best results in the easiest manner, then the Preziosi operation with beta ray is worth considering. Of course, the beta ray may also be combined with the surgeon's own favourite glaucoma operation.

The following are the details of the beta ray application, kindly supplied by Dr. K. W. Mead of the Queensland Radium Institute:

40 millicuries of radioactive $\mathrm{Sr}^{90}$ in a plate $12 \mathrm{~mm}$. diameter, delivering $1,000 \mathrm{r}$ per minute. Lead foil $0 \cdot 3-\mathrm{mm}$. thick with a $5-\mathrm{mm}$. circular hole.

Yours faithfully,

Brisbane Clinic,

malcolm E. Cameron.

79 WICKHAM TERRACE,

Brisbane, Australia.

February 29, 1960.

\section{REFERENCE}

EPSTEIN, E. (1959). Brit. J. Ophthal., 43, 641. 